\begin{tabular}{c|c|c}
\hline \hline Vol. 131: $\mathbf{3 9 - 4 8 , 2 0 1 8}$ & DISEASES OF AQUATIC ORGANISMS \\
https://doi.org/10.3354/dao03279 & Dis Aquat Org & Published October 16 \\
\hline
\end{tabular}

OPEN ACCESS $C$ BY

\title{
Ethoxyquin: a feed additive that poses a risk for aquatic life
}

\author{
Sophia Egloff, Constanze Pietsch* \\ Institute of Natural Resource Sciences (IUNR), Zurich University of Applied Sciences (ZHAW), Grüental, \\ PO Box 8820 Wädenswil, Switzerland
}

\begin{abstract}
Ethoxyquin (EQ) is an antioxidant that has, to date, been commonly used in feed production. Reports on the detrimental effects of this substance on vertebrates are growing, but effects in aquatic systems have rarely been described. Therefore, the present study was conducted using serial concentrations of EQ ranging from 0.03 to $16.5 \mathrm{mg} \mathrm{l}^{-1}$ to determine effects on 3 types of aquatic organisms. In zebrafish, $5 \mathrm{mg} \mathrm{l}^{-1}$ EQ caused mortality (25\%) and a further $62.5 \%$ of the embryos showed yolk sac edema as well as deformed bodies or missing eyes. Furthermore, all the investigated EQ concentrations decreased the heart rate of the embryos. The lowest observed effect level was $0.31 \mathrm{mg} \mathrm{l}^{-1}$. In addition to zebrafish, the study also used water fleas Daphnia magna and green algae (Scenedesmus obliquus and Chlorella vulgaris). These treatments revealed that daphnids are also sensitive to EQ, exhibiting detrimental effects with a half-maximal effective concentration $\left(\mathrm{EC}_{50}\right)$ of $2.65 \mathrm{mg} \mathrm{l}^{-1}$ after $48 \mathrm{~h}$ of exposure. The algae appeared to be at least 2 times less sensitive to EQ than fish embryos or daphnids. The results were used to calculate the risk for aquatic life resulting in a maximum tolerable level of $1 \mathrm{\mu g} \mathrm{l}^{-1}$ for fish embryos and daphnids, with a safety factor of 300. According to current knowledge, this does not exceed environmental concentrations of this substance. However, this study raises further concern about the (until recently) legal maximum tolerable EQ levels in fish feeding and the rather slow pace at which authorization to use EQ as a feed additive for diverse animals in Europe is being suspended.
\end{abstract}

KEY WORDS: Feed additive $\cdot$ Antioxidant $\cdot$ Pesticide $\cdot$ Toxicity $\cdot$ Embryo $\cdot$ Teratogen $\cdot$ Zebrafish . Danio rerio $\cdot$ Water flea $\cdot$ Daphnia $\cdot$ Algae $\cdot$ Scenedesmus $\cdot$ Chlorella

\section{INTRODUCTION}

Initially registered as a pesticide in 1965, ethoxyquin (EQ; 6-ethoxy-1,2-dihydro-2,2,4-trimethylquinolin; E324) is a broadly used antioxidant and has been used as a post-harvest indoor application for fruits (US EPA 2004). EQ has not been permitted as a pesticide in Europe since 2013, but can still be used as a feed additive (EFSA 2013). In addition, EQ is a major antioxidant in fish meal, and is used for longdistance overseas transport of fish meal to reduce oxidation and the subsequent danger of self-ignition (UNECE 2005). To date, as much as $150 \mathrm{mg} \mathrm{EQ} \mathrm{kg}{ }^{-1}$

${ }^{*}$ Corresponding author: constanze.pietsch@zhaw.ch feed has been allowed to be added to animal feed (EEC 1990). Since EQ was suspected of being carcinogenic, the amount of EQ in feed for dogs was reduced from 150 to $75 \mathrm{mg} \mathrm{kg}^{-1}$ in 1977 . EQ is not permitted for use in human food, but considerable amounts of it enter our diet via contaminated food. The maximum allowable daily intake for humans is $5 \mu \mathrm{g} \mathrm{kg}^{-1}$ body weight, a value based on studies on dogs (Dewhurst 1998, Gupta \& Boobis 2005).

The major route of exposure to EQ for farmed fish is uptake through food. In carnivorous fish aquaculture, the inclusion of EQ-containing fish meal in the feed is common practice, resulting in traces of EQ

(C) The authors 2018. Open Access under Creative Commons by Attribution Licence. Use, distribution and reproduction are unrestricted. Authors and original publication must be credited. 
and EQ derivatives in fish muscle. Feeding of salmonids with EQ-contaminated feed has led to detectable amounts of the parent compound and its dimeric metabolite in fish muscle (Bohne et al. $2007 a, b, 2008)$. Similar results have also been obtained in halibut Hippoglossus hippoglossus and rainbow trout Oncorhynchus mykiss (Lundebye et al. 2010). A 2 wk recovery period was not sufficient to significantly reduce the detectable EQ values (Bohne et al. 2008). In the above-mentioned fish species, the dimeric metabolite of EQ reached approximately 10fold higher concentrations than the parent compound. Despite the presence of this metabolite in fish feed (Thorisson et al. 1992, He \& Ackman 2000), its pronounced occurrence in fish muscle was assumed to be due to the conversion of EQ to its dimer in fish (Bohne et al. 2007a,b, 2008). The reported occurrence of EQ and its metabolite in edible parts of fish at considerable concentrations led to the assumption that $E Q$, together with its metabolite, may reach the maximum tolerable threshold value for human consumption (Bohne et al. 2008).

The exposure of aquatic organisms to EQ via contaminated water is far less well studied. Irrespective of its extensive global use, knowledge of the occurrence of EQ in surface water is scarce. In 18 water samples from surface waters in Vietnam, EQ was detected at levels above the level of detection (LOD) of $8 \mathrm{ng} \mathrm{l}^{-1}$, and 6 of those samples showed EQ concentrations above $0.1 \mathrm{\mu g} \mathrm{l}^{-1}$ (Chau et al. 2015). The maximum level found in a water sample was $0.29 \mu \mathrm{g}$ $\mathrm{l}^{-1}$. This meant that (out of more than 1100 micropollutants that have been analysed) EQ was 1 of the 24 most frequently occurring substances in water bodies in Vietnam. The relatively low EQ concentrations in open surface waters might be due to its rapid degradation by irradiation (Bintou et al. 2015), but this might not be the case for recirculating aquaculture facilities.

Several studies have reported detrimental effects of EQ in animals, including weight loss, changes in liver and kidneys, anaemia, and increased lethargy (reviewed by Błaszczyk et al. 2013). The known effects in fish are restricted to reports of liver changes, effects on the immune system, changes to condition factors and growth performance, and increased mortality (Yamashita et al. 2009, Wang et al. 2010, 2015, Bogevik et al. 2016). The Pan Pesticide Database (www.pesticideinfo. org) listed a half-maximal lethal concentration $\left(\mathrm{LC}_{50}\right)$ value of $18 \mathrm{mg} \mathrm{l}^{-1}$ after $96 \mathrm{~h}$ for EQ in juvenile rainbow trout. To date, the possible effects in vertebrates, including fish, of the relatively stable metabolites of EQ remain unknown. However, feeding rats with $12.5 \mathrm{mg}$ of the EQ dimer $\mathrm{kg}^{-1}$ body weight $\mathrm{d}^{-1}$ influenced liver enzyme activity in a similar way to the parent compound (Ørnsrud et al. 2011).

The toxicity of EQ on aquatic life has rarely been investigated, and even less is known about the toxicity of EQ metabolites. In addition, chronic studies on the effects of EQ on aquatic species are lacking. Therefore, the data obtained from the present study have been used to establish effect threshold values, which were used for further risk calculations. A toxicological profile should be established for quantitative risk assessments, and concentrations of concern should be defined (US EPA 2012). Due to the inconclusive data, a safety factor of 300 must be applied to the calculations (WHO 2012). Accordingly, the present study evaluated the toxicity of water-borne EQ for different aquatic organisms, including zebrafish Danio rerio embryos, daphnids Daphnia magna, and green algae (Chlorella vulgaris and Scenedesmus obliquus), in order to derive a risk.

\section{MATERIALS AND METHODS}

All chemicals were obtained from Sigma, including ethoxyquin (product no. E8260, lot no. 074K0026V).

\section{Exposure of zebrafish and subsequent analyses}

The zebrafish originating from the wild-type UFZOBI strain spawned at the Swiss Federal Institute of Aquatic Science and Technology (EAWAG) facilities (Dübendorf, Switzerland) in May and June 2016. The test was conducted according to the DIN-norm 38415-6 (DIN 2001), starting with zebrafish eggs at 4 $\mathrm{h}$ post-fertilization. The eggs were incubated with different EQ concentrations in sterile ISO water containing calcium chloride 2-hydrate $\left(294 \mathrm{mg} \mathrm{l}^{-1}\right)$, magnesium sulfate-7-hydrate $\left(123.3 \mathrm{mg} \mathrm{l}^{-1}\right)$, sodium hydrogen carbonate $\left(63 \mathrm{mg} \mathrm{l}^{-1}\right)$, and potassium chloride $\left(5.5 \mathrm{mg} \mathrm{l}^{-1}\right)$. The $\mathrm{pH}$ was 7.4 . In addition, 3,4 dichloroaniline $(3,4-\mathrm{D})$ was used at concentrations of between 0.25 and $4 \mathrm{mg} \mathrm{l}^{-1}$ as a positive control, since according to the revised Organisation for Economic Cooperation and Development (OECD) guideline, a new criterion for early life stage tests with zebrafish includes the observation that an exposure to $4 \mathrm{mg} \mathrm{l}^{-1}$ of this substance results in at least $30 \%$ mortality after 96 h of exposure (EURL ECVAM 2014). 
For the range-finding experiment, 4 plates with 4 embryos for each treatment were incubated for $96 \mathrm{~h}$ at $28^{\circ} \mathrm{C}$. Each plate contained control exposures with eggs exposed to ISO water only and to a solvent control containing the same ethanol content as the EQ treatments $(0.1 \% \mathrm{v} / \mathrm{v})$. In the second experiment, the fish eggs were exposed to EQ concentrations of $5 \mathrm{mg}$ $1^{-1}$ and lower, at an incubation temperature of $27.5^{\circ} \mathrm{C}$ to more accurately determine the half-maximal effective concentration $\left(\mathrm{EC}_{50}\right)$ value for $\mathrm{EQ}$. Embryonal development was determined using a microscope (Leica Type 090-135.006) at 24, 48, 72, and $96 \mathrm{~h}$ post-fertilization. For the subsequent experiment, 4 plates with 4 embryos for each treatment were incubated for $96 \mathrm{~h}$ at $27^{\circ} \mathrm{C}$. Mortality, stage of development, the presence of eyes, somites, the movement of the tail, and possible occurrence of oedema were noted after $24 \mathrm{~h}$ of exposure. After 48 and $72 \mathrm{~h}$ of exposure, pigmentation and blood flow were also recorded. At 48 and $72 \mathrm{~h}$ post-fertilization, the heart rate of each living embryo was assessed for 20 to $30 \mathrm{~s}$ and the heart rate (in beats $\mathrm{min}^{-1}$ ) was calculated.

\section{Exposure of daphnids and subsequent analyses}

Daphnia magna specimens were obtained from the University of Basel (Switzerland) and the daphnids were grown in Aachener Daphnien Medium (ADaM) according to Klüttgen et al. (1994) for several months. Juveniles at a maximum age of $24 \mathrm{~h}$ were selected for exposures to EQ concentrations of $8.25 \mathrm{mg} \mathrm{l}^{-1}$ or serial dilutions of this concentration. Test solutions in ADaM were prepared in 24well microtiter plates (TPP, Faust Labor). The solvent control was supplemented with $0.0125 \%$ ethanol, and the control contained only ADaM. All plates were incubated at room temperature and a $16 \mathrm{~h}$ light:8 h dark cycle. According to the OECD guideline for the evaluation of immobilization of daphnids, the animals were evaluated after 24 and $48 \mathrm{~h}$ of exposure (OECD 1984).

\section{Exposure of algae and subsequent analyses}

Serial dilutions of a $16.5 \mathrm{mg} \mathrm{l}^{-1}$ EQ concentration in $0.1 \%$ algae medium (Brányiková et al. 2011) were prepared in 96-well microtiter plates (TPP, Faust Labor) using 8 wells treatment ${ }^{-1}$, including a negative control only containing medium supplemented with $0.0125 \%$ ethanol. Each well contained $200 \mu \mathrm{l}$ of medium. All treatments were prepared on triplicate plates. The CCALA 454 strain of Scenedesmus obliquus and CCALA 256 strain of Chlorella vulgaris were obtained from the Culture Collection of Autotrophic Organisms (Trebon, Czech Republic) and were grown in the algae medium. A volume of $10 \mu \mathrm{l}$ of algal cells was added to each well, except for the medium control wells to which the same amount of only medium was added. For C. vulgaris, 59500 cells were added to the corresponding wells; 28800 cells were used for $S$. obliquus. Cell numbers were determined by counting algal solutions in an improved Neubauer chamber (Carl Roth). The prepared microtiter plates were analysed for their absorbance at a wavelength of $750 \mathrm{~nm}$ and their chlorophyll fluorescence (using excitation at $420 \mathrm{~nm}$ and measuring light emission at $683 \mathrm{~nm}$ ) in a plate reader (Infinite M200 Pro, Tecan). This was performed at the beginning of the experiment, then after 24 and $48 \mathrm{~h}$ of incubation at $25^{\circ} \mathrm{C}$ with $4.5 \% \mathrm{CO}_{2}$ in an Multitron Pro incubator (Infors) under constant orbital shaking at $400 \mathrm{rpm}$ on an Eppendorf Thermomixer R mixer/ incubator integrated shaker (Eppendorf).

\section{Analysis of EQ}

Cooled samples were sent to Eurofins Scientific (Schönenwerd, Switzerland) for EQ analysis by means of an accredited GC-MS method. In the medium used for zebrafish embryo exposures, only EQ was analysed. In the daphnia and algae medium, $\mathrm{EQ}$ and the concentration of the EQ dimer were assessed.

\section{Statistics}

Chi-squared statistics were employed to compare the incidence of lethal and non-lethal damage to the embryos by using the Monte Carlo approximation (with a confidence interval of $99 \%$ ) to the Pearson chi-squared test. The heart rates were compared by using Mann-Whitney U-tests and Kruskal-Wallis tests in SPSS v.21 (SPSS). Differences between treatment groups were considered statistically significant when $\mathrm{p}<0.05$.

\section{Risk assessment}

Based on recommendations (US EPA 2012), toxicological profiles were established and concentrations of concern were derived. The first part of such 
a risk assessment is the assessment of toxicity of a chemical.

To assess risk, it was necessary to perform an exposure assessment. For substances in the environment, it is generally assumed that the more the substances are added to ecosystems, the higher the exposure potential. EQ is a widely used industrial chemical that is produced every year in large amounts. Exposure of fish in aquaculture certainly includes exposure from food. Since EQ is a lipophilic compound, this exposure route is the most important one. However, recent reports on EQ detection in surface water samples have raised concerns about how common a micropollutant EQ might be (Chau et al. 2015). No sufficient data on the occurrence in water of the more hydrophilic metabolites of EQ are currently available, and they have rarely been investigated, even in aquatic organisms (Bohne et al. 2007a,b, 2008). For this reason, metabolites of EQ cannot be included in this study.

In order to characterise the risk, toxic levels need to be compared to the actual exposure situation and specific safety factors applied. According to Annex VI of Directive 91/414/EEC of EU Legislation (EEC 1991), a factor of 10 should be chosen for risk assessment of chronic effects. However, up-to-date chronic studies are not available for EQ. In conventional risk assessments, a safety factor of 50 is used to derive predicted no-effect concentrations (PNECs) to compensate for uncertainty in measurements due to accumulation rates, metabolism, intra-species and inter-species variation, differences related to age, sex, nutritional status and time of exposure, and the uncertainty of extrapolation of laboratory studies to the field. Further recommendations include basing calculations on the most sensitive species, which is also unknown for EQ. Thus, this approach was not applicable to the current data set. Given these serious limitations, a safety factor of 50 was recommended to derive PNECs, since this is the value recommended for chronic toxicity data not necessarily derived from the most sensitive species (OPP 2002). The reasons for this decision are as follows: for acute studies, a more conservative factor of 100 is recommended, especially when the above-mentioned sources make a strong contribution to overall uncertainty (OPP 2002). Consequently, the US EPA recommended a safety factor of 100 for acute, dietary exposure of higher vertebrates (10 for each, inter- and intraspecific variation, respectively).

The US EPA safety factors also incorporate a factor 3 for uncertainties related to inter- and intraspecies- specific differences, extrapolation of sub-chronic to chronic values and the use of lowest observable effect levels (LOELs) instead of no observed effect levels (NOELs). Finally, the Food Safety Commission of Japan (FSCJ 2014) conducted a risk assessment for EQ and applied a safety factor of 300 (10 for species difference, 10 for individual difference, and 3 because it was assumed to be more appropriate to adopt the lowest observed adverse effect level [LOAEL]). So far, no safe values could be derived from summarising studies on Atlantic salmon, Atlantic croaker, and Nile tilapia (Bohne et al. 2008, Yamashita et al. 2009, Wang et al. 2010, EFSA FEEDAP 2015). Therefore, dose-response studies were conducted in different aquatic organisms for the present study.

\section{RESULTS}

The toxicity data in the different assays were used to derive LOELs after 24 and $48 \mathrm{~h}$ of exposure to EQ (Table 1). The results of the individual experiments are presented in the following sections.

\section{Expt 1 with zebrafish}

After $24 \mathrm{~h}$ of exposure, all fish eggs exposed to EQ concentrations of $10 \mathrm{mg} \mathrm{l}^{-1}$ or higher died (Fig. 1). Mortality in the control and in the solvent control was $12.5 \%$. Fish eggs exposed to $5 \mathrm{mg} \mathrm{l}^{-1} \mathrm{EQ}$ showed a significantly higher mortality of $25 \%$ and a further $62.5 \%$ of the embryos showed damage, such as severe yolk sac deformation and reduced yolk sac transparency. At this time point the larvae were not yet pigmented.

Table 1. Lowest observable effect levels (LOELs) of ethoxyquin (EQ) for the corresponding toxicity tests and calculation of predicted no effect concentrations (PNECs) when applying various safety factors

\begin{tabular}{|lcc|}
\hline \multirow{2}{*}{ Organism } & \multicolumn{3}{c|}{ LOEL $\left(\mathrm{mg} \mathrm{l}^{-1}\right)$} \\
& $24 \mathrm{~h}$ & $48 \mathrm{~h}$ \\
\hline Danio rerio & 1.25 & 0.31 \\
Daphnia magna & 0.26 & 0.52 \\
Chlorella vulgaris & 2.06 & 4.31 \\
Scenedesmus obliquus & 4.31 & 4.31 \\
PNEC plus safety 50 & 0.039 & 0.047 \\
PNEC plus safety 100 & 0.020 & 0.024 \\
PNEC plus safety 300 & 0.007 & 0.008 \\
PNEC plus safety 300 (animals only) & 0.003 & 0.001 \\
\hline
\end{tabular}




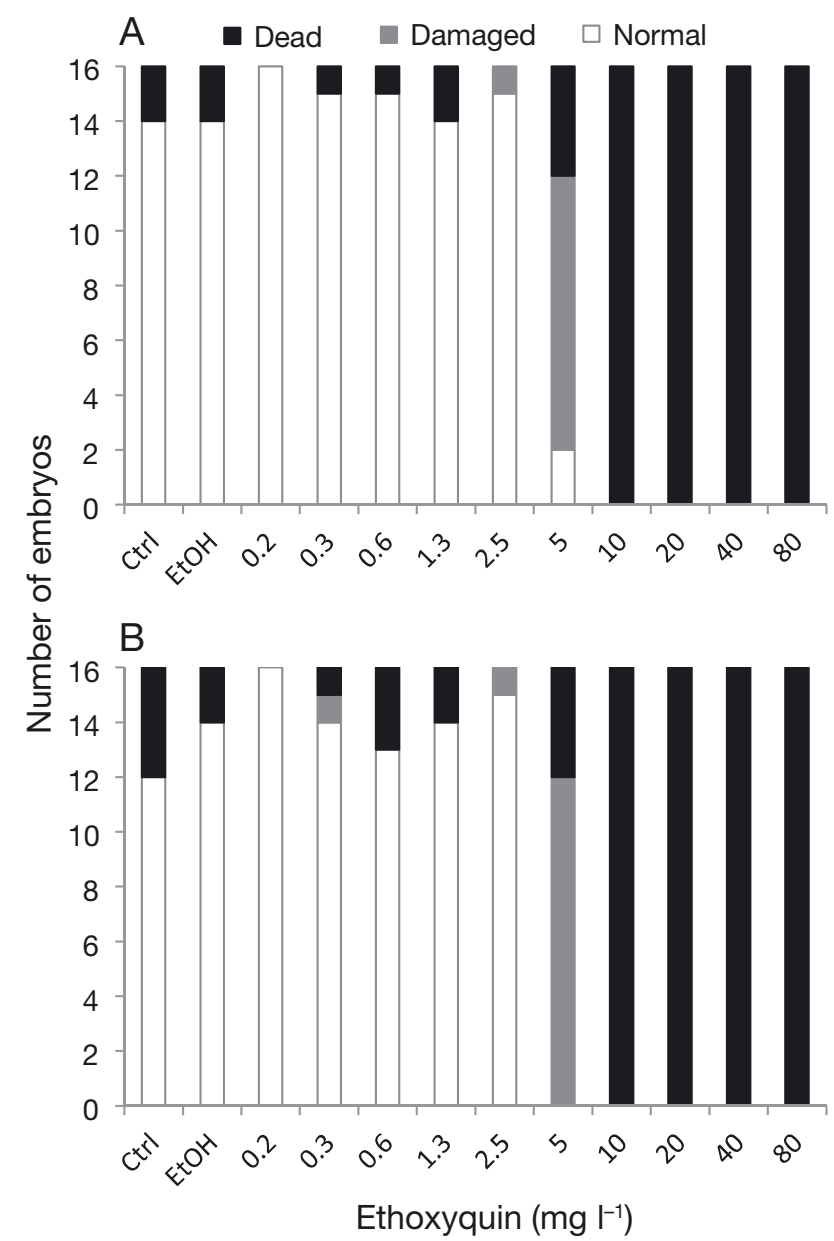

Fig. 1. Differences in the development of zebrafish embryos (Danio rerio) after (A) $24 \mathrm{~h}$ and (B) $48 \mathrm{~h}$ of exposure to ethoxyquin in the first experiment $\left(n=16\right.$ treatment $\left.^{-1}\right)$. Negative control with ISO water

After $48 \mathrm{~h}$ of exposure, the pigmentation of the embryos had started, the eye of normally developed embryos was dark-pigmented, and yolk sac depletion was in progress. Mortality increased further in the groups exposed to $5 \mathrm{mg} \mathrm{l}^{-1} \mathrm{EQ}$ (Fig. 1). Some EQexposed embryos not only showed yolk sac deformations, but also reduced eye development, and pigmentation was missing in some embryos (Fig. 2). One embryo also showed deformation of the spine (Fig. 2B). From this first range-finding experiment, it was observed that the $\mathrm{LC}_{50}$ for $\mathrm{EQ}$ in zebrafish embryo ranged between 10 and $20 \mathrm{mg} \mathrm{l}^{-1}$. Calculated $\mathrm{LC}_{50}$ values were found to be 14.7 to $14.8 \mathrm{mg} \mathrm{l}^{-1}$ for 24 and $48 \mathrm{~h}$ of exposure, respectively. The $\mathrm{EC}_{50}$ values for any damage (including dead embryos) were found to be 8.1 and $7.8 \mathrm{mg} \mathrm{l}^{-1}$ for 24 and $48 \mathrm{~h}$ of exposure, respectively. A second experiment was conducted to further define the $\mathrm{EC}_{50}$ values.
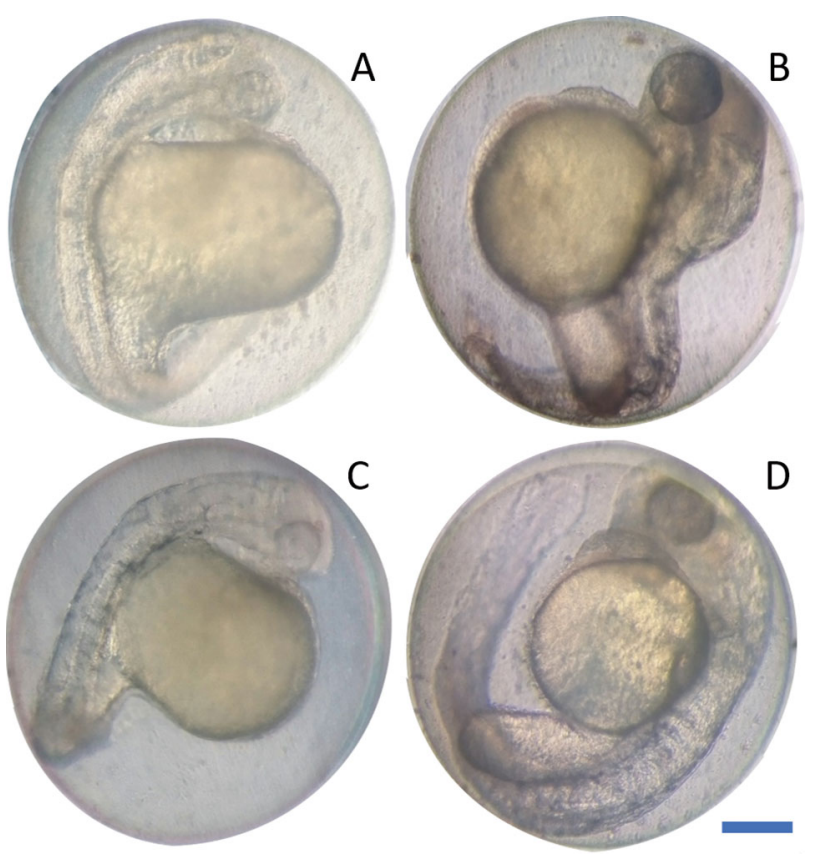

Fig. 2. Developmental problems of zebrafish Danio rerio in the first experiment, showing $(A, C)$ increased yolk turbidity, yolk sac deformation, and a lack of eye pigmentation, and (B) spinal deformation in embryos after $48 \mathrm{~h}$ of exposure to $5 \mathrm{mg}$ $\mathrm{l}^{-1}$ ethoxyquin (A-C) compared with a control embryo (D). Magnification 100× (Leica microscope). Scale bar $=200 \mu \mathrm{m}$

\section{Expt 2 with zebrafish}

In this experiment, the detrimental effects on zebrafish embryos were confirmed and the resulting calculations exhibited a polynomic relationship $\left(y=-2.3817 x^{2}\right.$ $\left.+22.78 x+24.355 ; \mathrm{r}^{2}=0.67\right)$. Consequently, an $\mathrm{EC}_{50}$ value of $1.30 \mathrm{mg} \mathrm{l}^{-1}$ was calculated after $24 \mathrm{~h}$ of exposure. However, the detrimental effects on the embryos showed an $\mathrm{EC}_{50}$ value of $3.70 \mathrm{mg} \mathrm{l}^{-1}\left(y=1.2957 \mathrm{x}^{2}+\right.$ $\left.1.4452 x+26.934 ; r^{2}=0.64\right)$ after $48 \mathrm{~h}$ of exposure.

At $48 \mathrm{~h}$ post-fertilization, the heart rates of the embryos were assessed and combined with the results from the first experiment (Fig. 3), which showed a decrease in heart rate as EQ concentration increased $(y=$ $\left.-1.0263 x^{2}+0.15 x+96.533 ; \mathrm{r}^{2}=0.94\right)$, and an $\mathrm{EC}_{50}$ of $6.81 \mathrm{mg} \mathrm{l}^{-1}$ was estimated. Fig. 4 shows that the heart rate was significantly reduced in embryos exposed to $0.31 \mathrm{mg} \mathrm{l}^{-1} \mathrm{EQ}$. After $72 \mathrm{~h}$ of exposure, only the differences in heart rates between the control animals and embryos exposed to the 2 highest concentrations were assessed. These measurements showed that the heart rate of embryos exposed to these EQ concentrations were significantly lower than in the control animals. At 72 and $96 \mathrm{~h}$ of exposure, there was no pronounced increase in mortality. All embryos still living at $48 \mathrm{~h}$ of exposure also hatched by $96 \mathrm{~h}$, but the embryos ex- 


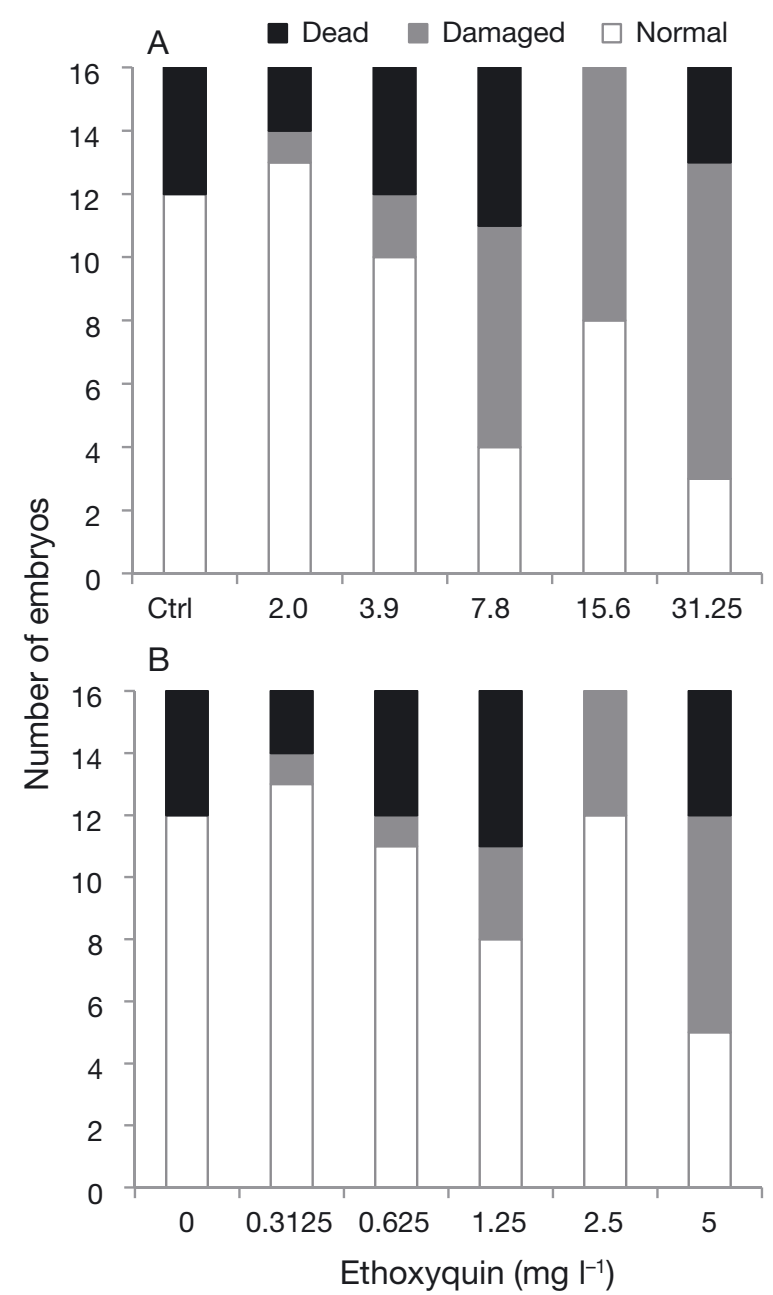

Fig. 3. Differences in the development of zebrafish embryos (Danio rerio) after (A) $24 \mathrm{~h}$ and (B) $48 \mathrm{~h}$ of exposure to ethoxyquin in the second experiment $\left(n=16\right.$ treatment $\left.^{-1}\right)$

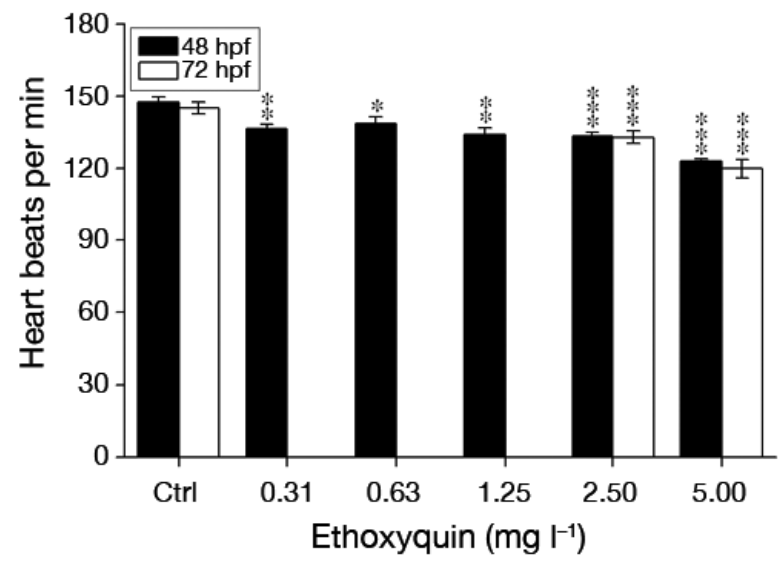

Fig. 4. Mean $( \pm \mathrm{SE})$ heart rate in zebrafish embryos (Danio rerio) after 48 and $72 \mathrm{~h}$ of exposure to different concentrations of ethoxyquin in the second experiment $(n=8$ to 12 treatment $^{-1}$ ). Asterisks indicate significant differences to control embryos tested with the Mann-Whitney $U$-test and the Kruskal-Wallis test $\left({ }^{*} \mathrm{p}<0.05 ;{ }^{* *} \mathrm{p}<0.01{ }^{* * *} \mathrm{p}<0.001\right)$ posed to the highest EQ concentration in this experiment ( $5 \mathrm{mg} \mathrm{l}^{-1}$ ) showed the slowest development.

As expected, exposure to the reference compound 3,4-D resulted in mortality of the fish embryos (Fig. 5). After $24 \mathrm{~h}$ of exposure, significant damage occurred in embryos that had been treated with $4 \mathrm{mg} \mathrm{l}^{-1} 3,4-\mathrm{D}$, but no significant increase in lethal damage was noted. After $48 \mathrm{~h}$ of exposure, damaged embryos were observed, delivering an $\mathrm{EC}_{50}$ value of $0.66 \mathrm{mg} \mathrm{l}^{-1}$, whereas the $\mathrm{LC}_{50}$ value was $3.03 \mathrm{mg} \mathrm{l}^{-1}$ (Table 2).

\section{Experiments with daphnids}

In the first experiment with daphnids, all animals exposed to concentrations higher than $10 \mathrm{mg} \mathrm{l}^{-1}$ died. The $\mathrm{LC}_{50}$ after $24 \mathrm{~h}$ of exposure to EQ was calculated to be $5.72 \mathrm{mg} \mathrm{l}^{-1}$. However, in the second experiment, the $\mathrm{EC}_{50}$ for detrimental effects (including damage or death) to daphnids was calculated to be $13.54 \mathrm{mg} \mathrm{l}^{-1}$

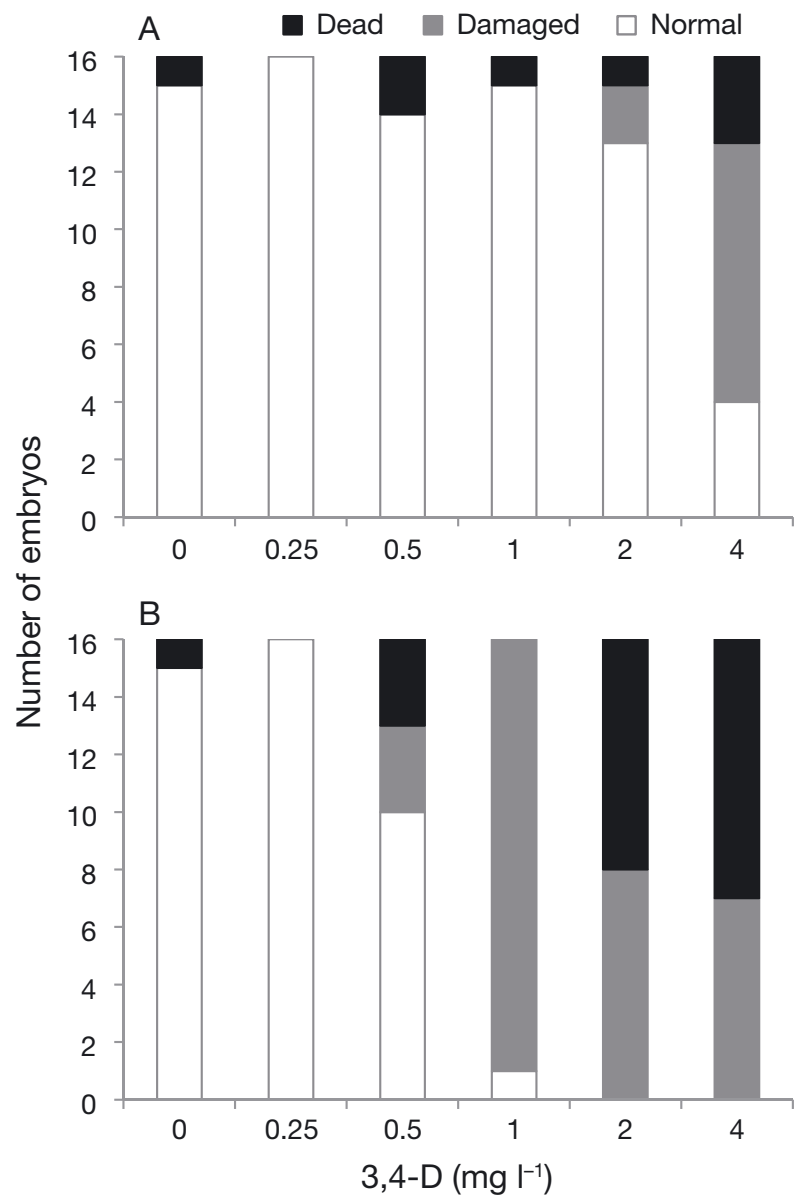

Fig. 5. Differences in the development of zebrafish embryos (Danio rerio) after (A) $24 \mathrm{~h}$ and (B) $48 \mathrm{~h}$ of exposure to the reference compound 3,4-dichloroaniline $(3,4$-D) $(\mathrm{n}=16$ treatment $^{-1}$ ) 
Table 2. Median effective concentration $\left(\mathrm{EC}_{50}\right)$ and mean lethal concentration $\left(\mathrm{LC}_{50}\right)$ values obtained for the exposure of Danio rerio embryos $(\mathrm{n}=18)$ to 3,4 -dichloroaniline for different test durations

\begin{tabular}{|lcc|}
\hline Exposure duration (h) & $\mathrm{EC}_{50}\left(\mathrm{mg} \mathrm{l}^{-1}\right)$ & $\mathrm{LC}_{50}\left(\mathrm{mg} \mathrm{l}^{-1}\right)$ \\
\hline 24 & 3.28 & 7.03 \\
48 & 0.66 & 3.03 \\
\hline
\end{tabular}

after $24 \mathrm{~h}$ of exposure to EQ and $2.65 \mathrm{mg} \mathrm{l}^{-1}$ after $48 \mathrm{~h}$ (Fig. 6).

\section{Experiments with green algae}

The cell numbers of Chlorella vulgaris increased over time and evaluation of the cell numbers after $24 \mathrm{~h}$ of exposure to EQ did not reveal a linear doseresponse relationship (Fig. 7, Table 3). However, exposure for $48 \mathrm{~h}$ to the highest EQ concentrations

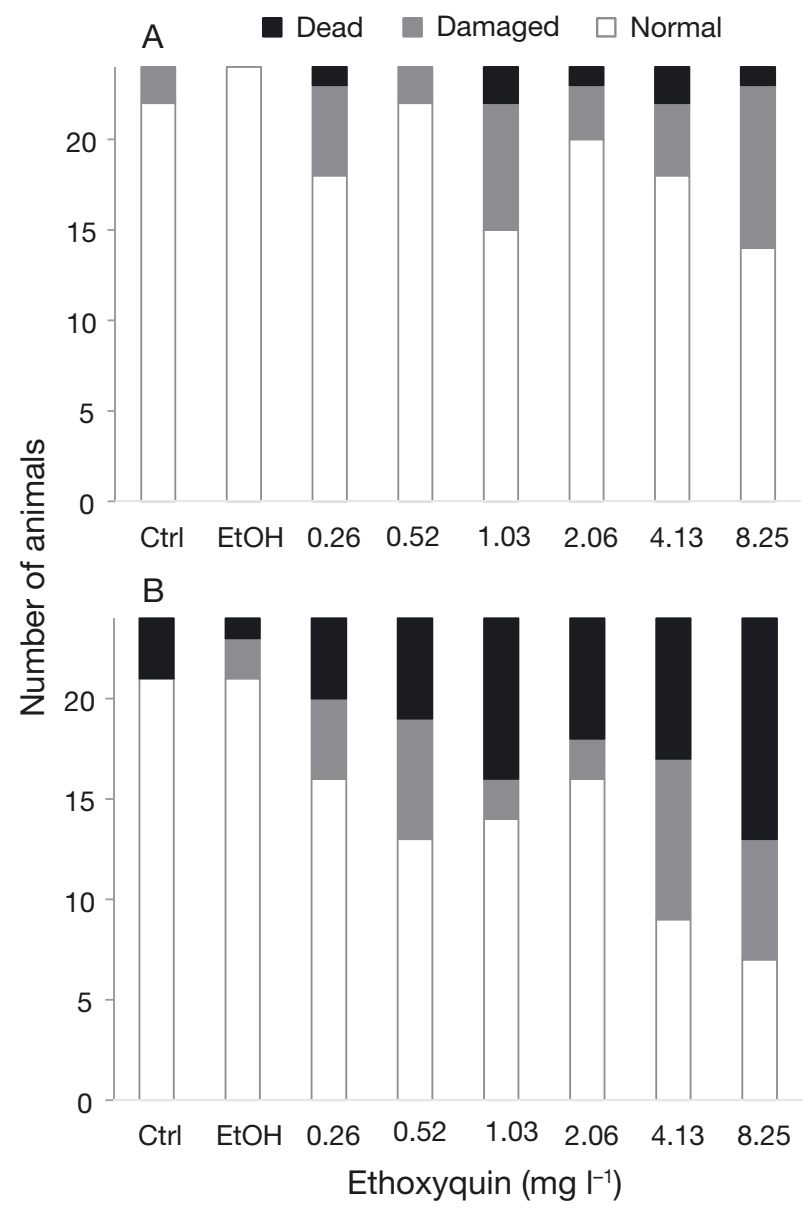

Fig. 6. Effects of ethoxyquin on water fleas Daphnia magna after (A) $24 \mathrm{~h}$ and (B) $48 \mathrm{~h}$ of exposure to different concentrations of ethoxyquin in the second experiment $\left(n=24\right.$ treatment $\left.^{-1}\right)$ reduced the cell numbers estimated by absorption at $750 \mathrm{~nm}$ by $12 \%$. Consequently, $\mathrm{LC}_{50}$ values for this species could not be observed during the experiments, but a relationship between the EQ concentrations and the reduction in cell numbers could be described $\left(y=0.067 x^{2}-1.7874 x+99.702 ; r^{2}=0.92\right)$. Since only viable cells respond with chlorophyll fluorescence emissions, the measured emitted light units were calculated based on a common light absorption value of 0.1 at $750 \mathrm{~nm}$ in order to allow comparison of the values (Fig. 8). For C. vulgaris, the relative fluorescence values after $48 \mathrm{~h}$ of exposure were $20 \%$ higher in the incubations with the highest EQ concentration than in the control incubations. Therefore, a decreasing fluorescence trend with increasing concentrations could be assumed from the data, which allowed an $\mathrm{EC}_{50}$ value of $27.03 \mathrm{mg} \mathrm{l}^{-1}\left(-0.2907 \mathrm{x}^{2}+\right.$ $\left.5.9696 x+101.07 ; r^{2}=0.92\right)$ to be calculated.

Scenedesmus obliquus showed less pronounced growth over time compared to C. vulgaris (Table 3) and also did not exhibit a reduction in cell numbers after exposure to EQ for $24 \mathrm{~h}$ (Fig. 7). In contrast to the other algal species, $S$. obliquus was found to be more sensitive to EQ. A $\mathrm{LC}_{50}$ value of $31.48 \mathrm{mg} \mathrm{l}^{-1}$

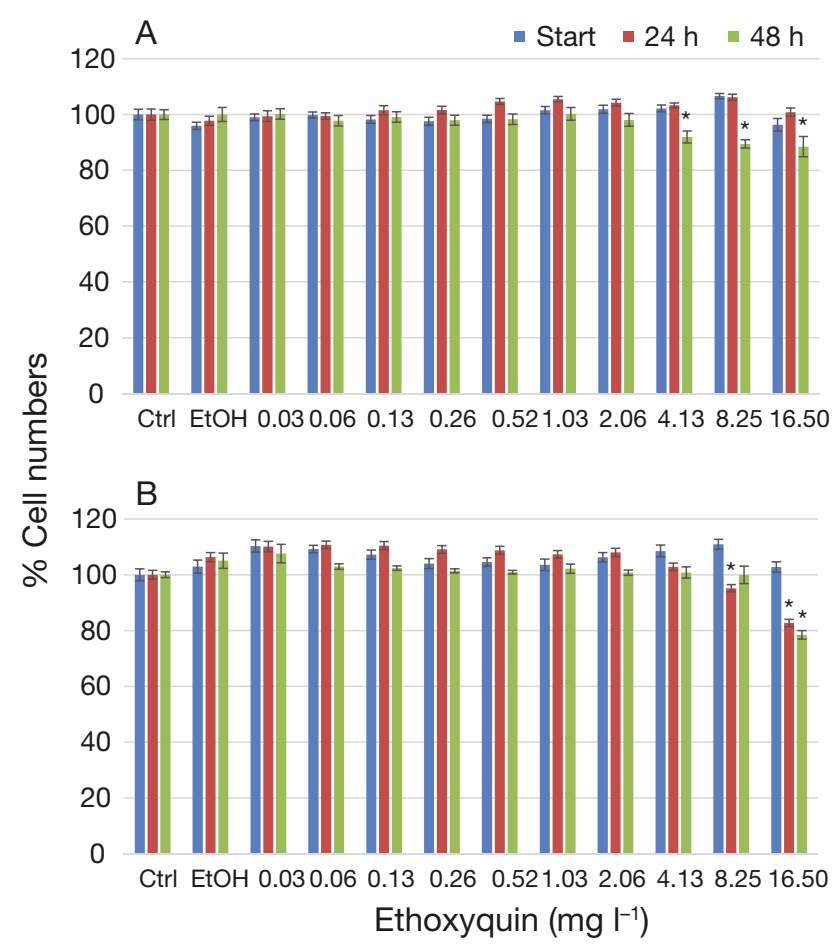

Fig. 7. Mean $( \pm \mathrm{SE})$ cell numbers estimated by absorption at $750 \mathrm{~nm}$ for green algae (A) Chlorella vulgaris and (B) Scenedesmus obliquus at the start of the experiment and after 24 and $48 \mathrm{~h}$ of exposure to different concentrations of ethoxyquin ( $\mathrm{n}=21$ wells treatment ${ }^{-1}$ ). ${ }^{*}$ Significant difference to control $(p<0.05)$ 
Table 3. Increase in biomass (assessed according to the difference in light absorption [OD] at $750 \mathrm{~nm}$ to evaluate cell numbers) obtained on exposure of Chlorella vulgaris and Scenedesmus obliquus algae ( $\mathrm{n}=21$ wells treatment $^{-1}$ ) to ethoxyquin $(E Q)$ over different test durations. Data are mean $\pm \mathrm{SE}$

\begin{tabular}{|c|c|c|c|c|}
\hline \multirow{3}{*}{$\begin{array}{l}\text { EQ con- } \\
\text { centration } \\
\left(\mathrm{mg} \mathrm{l}^{-1}\right)\end{array}$} & \multicolumn{4}{|c|}{ Biomass increase (\% of initial OD) } \\
\hline & \multirow{2}{*}{\multicolumn{2}{|c|}{ Chlorella $\overline{48 \mathrm{~h}}$}} & \multicolumn{2}{|c|}{ - Scenedesmus } \\
\hline & & & $24 \mathrm{~h}$ & $48 \mathrm{~h}$ \\
\hline Control & $109.6 \pm 5.8$ & $340.0 \pm 17.9$ & $73.7 \pm 4.0$ & $225.5 \pm 12.0$ \\
\hline Ethanol & $113.7 \pm 6.5$ & $358.1 \pm 21.0$ & $79.5 \pm 4.5$ & $232.4 \pm 14.8$ \\
\hline 0.03 & $110.2 \pm 6.0$ & $344.5 \pm 18.6$ & $73.2 \pm 3.8$ & $218.2 \pm 16.1$ \\
\hline 0.06 & $109.1 \pm 6.0$ & $330.2 \pm 17.9$ & $75.5 \pm 3.8$ & $205.6 \pm 10.3$ \\
\hline 0.13 & $116.7 \pm 6.7$ & $343.7 \pm 19.0$ & $78.4 \pm 4.1$ & $209.9 \pm 10.6$ \\
\hline 0.26 & $118.2 \pm 6.3$ & $342.0 \pm 19.5$ & $81.9 \pm 4.4$ & $217.2 \pm 11.3$ \\
\hline 0.52 & $122.9 \pm 6.7$ & $339.4 \pm 19.4$ & $80.3 \pm 4.3$ & $213.6 \pm 11.1$ \\
\hline 1.03 & $117.9 \pm 6.4$ & $333.5 \pm 18.7$ & $80.0 \pm 4.4$ & $221.7 \pm 13.2$ \\
\hline 2.06 & $114.6 \pm 6.2$ & $323.3 \pm 18.7$ & $76.3 \pm 4.0$ & $208.4 \pm 11.2$ \\
\hline 4.13 & $112.2 \pm 6.2$ & $295.7 \pm 17.2$ & $65.0 \pm 3.6$ & $202.3 \pm 11.8$ \\
\hline 8.25 & $108.7 \pm 5.7$ & $269.3 \pm 14.6$ & $49.4 \pm 2.5$ & $192.8 \pm 13.3$ \\
\hline 16.50 & $120.3 \pm 6.9$ & $305.4 \pm 22.6$ & $40.4 \pm 2.1$ & $148.5 \pm 8.2$ \\
\hline
\end{tabular}

$\left.0.2908 x+102.59 ; r^{2}=0.91\right)$. However, calculation of relative fluorescence values for this algal species showed that in the highest EQ incubation, $30 \%$ higher fluorescence values were obtained compared to the control incubations (Fig. 8).

\section{DISCUSSION}

This study revealed that EQ is toxic to aquatic organisms, with aquatic animals being more sensitive than algae to water-borne EQ exposure. During the experiments the algae displayed expected growth, and compared to the solvent controls, there were only minor reductions in cell numbers due to exposure to EQ after 24 and $48 \mathrm{~h}$ of exposure. This implies that algal EQ toxicity is slower than the toxicity in animal models. Increased fluorescence activity in the algae exposed to the higher EQ concentrations indicates a disturbance to photosystem function (Maxwell \& Johnson 2000). In contrast to the algae tests, the experiments with zebrafish embryos and daphnids allowed the calculation of $\mathrm{EC}_{50}$ and $\mathrm{LC}_{50}$ values.

Exposure to $3.03 \mathrm{mg} \mathrm{l}^{-1} 3,4$-D resulted in $50 \%$ mortality in fish embryos after only $48 \mathrm{~h}$ of exposure, and therefore fulfilled the criteria for the early life-stage test based on the revised OECD guidelines (EURL ECVAM 2014). Using a safety factor of 300 , a threshold EQ value for potential damage to aquatic fauna of $1 \mathrm{\mu g} \mathrm{l}^{-1}$ could be established. Since the maximum level that has been found in a water sample is $0.29 \mu \mathrm{g}$ $\mathrm{l}^{-1}$ (Chau et al. 2015), the environmental concentration of EQ can be assumed to be close to the PNEC in this study.

It can be assumed that the toxicity observed due to EQ exposure was due to the phenomenon that antioxidants can act as prooxidants when applied at high concentrations. In addition, phenolic antioxidants such as EQ are able form phenoxyl radicals which show typical prooxidant activities (Decker 1997, Sakihama et al. 2002). In solution, at least a part of EQ has been reported to exist in the free radical form (Skaare \& Henriksen 1975, Sakihama et al. 2002). As a consequence, oxygen species can occur which cause oxidative damage. In fish, liver changes and adverse effects on the immune system, growth, and increased mortality have been observed (Yamashita et al. 2009, Wang et al. 2010, 2015, Bogevik et was observed for this species $\left(y=-0.0188 x^{2}-1.2611 x\right.$ $+108.34 ; \mathrm{r}^{2}=0.87$ ) after $24 \mathrm{~h}$ of exposure and a $\mathrm{LC}_{50}$ value of $23.84 \mathrm{mg} \mathrm{l}^{-1}$ after $48 \mathrm{~h}\left(y=-0.1047 \mathrm{x}^{2}+\right.$ 
al. 2016), which may be related to the prooxidant characteristics of EQ. The reason why the green algae were less affected by EQ than the animal species may be the high antioxidative capacity of algae of the genera Chlorella and Scenedesmus, probably bestowed by their considerable polyphenolic and flavonoid contents (Stoica et al. 2013, Ahmed 2016, Strejckova et al. 2017).

Compared to exposure to EQ in diets, the sensitivity of zebrafish embryos to EQ via the surrounding medium was high. Juvenile Japanese seabass Lateolabrax japonicus should not be exposed to foodborne EQ concentrations of more than $13.78 \mathrm{mg}$ EQ $\mathrm{kg}^{-1}$ diet for $12 \mathrm{wk}$ in order to avoid growth depression as a result of EQ exposure (Wang et al. 2015). Nevertheless, environmental concentrations are considerably lower in water than in feed, although exact data for recirculating aquaculture systems are currently not available.

\section{CONCLUSION}

The present study raises concern about the (until recently) legal maximum tolerable EQ levels in fish feed in the European Union, and the relatively slow pace at which EQ authorization as a feed additive for diverse animals in Europe is being suspended. However, further studies are needed to establish no-effect concentration levels and to increase our knowledge of environmental EQ concentrations in different countries.

Acknowledgements. The authors thank Prof. Kristin Schirmer and Dr. Stephan Fischer (EAWAG, Dübendorf, Switzerland) for providing the zebrafish eggs for the tests. The authors are grateful to Mathias Sigrist (ZHAW Wädenswil) for additional help with the laboratory work. The language corrections to the manuscript were done by Darren Mace (ZHAW Wädenswil).

\section{LITERATURE CITED}

Ahmed EA (2016) Antimicrobial activity of microalgal extracts isolated from Baharia Oasis, Egypt. Glob Adv Res J Microbiol 5:033-041

Bintou AT, Bianco A, Mailhot G, Brigante M (2015) A new insight into ethoxyquin fate in surface waters: stability, direct and indirect photochemical behaviour and the identification of main products. J Photochem Photobiol Chem 311:118-126

Błaszczyk A, Augustyniak A, Skolimowski J (2013) Ethoxyquin: an antioxidant used in animal feed. Int J Food Sci 2013:585931

Bogevik AS, Kousoulaki K, Skiftesvik AB, Opstad I (2016) Fishmeal quality and ethoxyquin effects on the weaning performance of ballan wrasse (Labrus bergylta) larvae. Aquacult Nutr 22:46-50

* Bohne VJB, Hove H, Hamre K (2007a) Simultaneous quantitative determination of the synthetic antioxidant ethoxyquin and its major metabolite in Atlantic salmon (Salmo salar, L), ethoxyquin dimer, by reversed-phase high performance liquid chromatography with fluorescence detection. J AOAC Int 90:587-597

Bohne VJB, Hamre K, Arukwe A (2007b) Hepatic metabolism, phase I and II biotransformation enzymes in Atlantic salmon (Salmo salar, L) during a 12 week feeding period with graded levels of the synthetic antioxidant, ethoxyquin. Food Chem Toxicol 45:733-746

Bohne VJB, Lundebye AK, Hamre K (2008) Accumulation and depuration of the synthetic antioxidant ethoxyquin in the muscle of Atlantic salmon (Salmo salar L.). Food Chem Toxicol 46:1834-1843

Brányiková I, Maršálková B, Doucha J, Brányik T, Bišová K, Zachleder V, Vítová M (2011) Microalgae-novel highly efficient starch producers. Biotechnol Bioeng 108:766-776

Chau HTC, Kadokami K, Duong HT, Kong L, Nguyen TT, Nguyen TQ, Ito Y (2015) Occurrence of 1153 organic micropollutants in the aquatic environment of Vietnam. Environ Sci Pollut Res 25:7147-7156

* Decker EA (1997) Phenolics: Prooxidants or antioxidants? Nutr Rev 55:396-398

Dewhurst I (1998) Ethoxyquin. In: Pesticide residues in food-1998: toxicological and environmental evaluations. Report of the joint meeting of the FAO Panel of Experts on Pesticide Residues in Food and the Environment and the WHO Core Assessment Group. www. inchem.org/documents/jmpr/jmpmono/v098pr09.htm (accessed in April 2017)

DIN (Deutsches Institut fur Normung) (2001) DIN-Norm 38415-6 T6. Deutsche Einheitsverfahren zur Wasser-, Abwasser- und Schlammuntersuchung. Suborganismische Testverfahren (Gruppe T), Teil 6: Giftigkeit gegenüber Fischen, Bestimmung der nicht akut giftigen Wirkung von Abwasser auf die Entwicklung von Fischeiern über Verdünnungsstufen (T6). Deutsches Institut für Normung, Berlin

EEC (European Economic Community) (1990) Council Regulation (EEC) No. 2377/90 of 26 June 1990 laying down a Community procedure for the establishment of maximum residue limits of veterinary medicinal products in foodstuffs of animal origin. Off J Eur Comm L 224:1-8

EEC (European Economic Community) (1991) Annex VI of the Council Directive 91/414/EEC concerning the placing of plant protection products on the market. Off $\mathrm{J}$ EC L 230:0001-0032

EFSA (European Food Safety Authority) (2013) Reasoned opinion on the review of the existing maximum residue levels (MRLs) for ethoxyquin according to Article 12 of Regulation (EC) No 396/2005. EFSA J 11:3231

* EFSA FEEDAP (Panel on Additives and Products or Substances used in Animal Feed) (2015) Safety and efficacy of ethoxyquin (6-ethoxy-1,2-dihydro-2,2,4-trimethylquinoline) for all animal species. EFSA J 13:4272

EU (European Union) (2017) Commission Implementing Regulation (EU) 2017/962 of 7 June 2017 suspending the authorisation of ethoxyquin as a feed additive for all animal species and categories. Off J Eur Comm L 145: 13-17

EURL ECVAM (European Union Reference Laboratory for Alternatives to Animal Testing) (2014) Recommendation 
on the zebrafish embryo acute toxicity test method (ZFET) for acute fish testing toxicity. European Commission Joint Research Centre, Institute for Health and Consumer Protection. Scientific and Technical Research Series EUR 26710. Publications Office of the European Union, Luxembourg doi: 10.2788/87475

FSCJ (Food Safety Commission of Japan) (2014) Ethoxyquin. Summary (Indianap Ind) 2:14-15

* Gupta PK, Boobis A (2005) Ethoxyquin (Addendum). Joint FAO/WHO Meeting on Pesticide Residues (JMPR) 2005. FAO/WHO, Rome, p 241-253

He P, Ackman RG (2000) HPLC determination of ethoxyquin and its major oxidation products in fresh and stored fish meals and fish feeds. J Sci Food Agric 80:10-16

Klüttgen B, Dülmer U, Engels M, Ratte HT (1994) ADaM, an artificial freshwater for the culture of zooplankton. Water Res 28:743-746

Lundebye AK, Hove H, Måge A, Bohne VJB, Hamre K (2010) Levels of synthetic antioxidants (ethoxyquin, butylated hydroxytoluene and butylated hydroxyanisole) in fish feed and commercially farmed fish. Food Addit Contam 27:1652-1657

Maxwell K, Johnson GN (2000) Chlorophyll fluorescencea practical guide. J Exp Bot 51:659-668

OECD (Organisation for Economic Cooperation and Development) (1984) Daphnia sp., acute immobilisation test and reproduction test. OECD guideline for testing chemicals No. 202. Organisation for Economic Cooperation and Development, Paris

OPP (Office of Pesticide Programs) (2002) Consideration of the FQPA Safety factor and other uncertainty factors in cumulative risk assessment of chemicals sharing a common mechanism of toxicity. Office of Pesticide Programs, US Environmental Protection Agency, Washington DC

Ørnsrud R, Arukwe A, Bohne V, Pavlikova N, Lundbye AK (2011) Investigations on the metabolism and potentially adverse effects of ethoxyquin dimer, a major metabolite of the synthetic antioxidant ethoxyquin in salmon muscle. J Food Prot 74:1574-1580

Sakihama Y, Cohen MF, Grace SC, Yamasaki H (2002) Plant phenolic antioxidant and prooxidant activities: phenolics-induced oxidative damage mediated by metals in plants. Toxicology 177:67-80

Skaare JU, Henriksen T (1975) Free radical formation in the antioxidant ethoxyquin. J Sci Food Agric 26:1647-1654

Stoica R, Velea S, Ilie L, Calugareanu M, Ghimis SB, Ion RM

Editorial responsibility: Stephen Feist, Weymouth, UK
(2013) The influence of ethanol concentration on the total phenolics and antioxidant activity of Scenedesmus opoliensis algal biomass extracts. Rev Chim (Bucharest) 64:304-306

Strejckova A, Kolackova M, Vaneckova T, Bytesnikova Z and others (2017) Effect of zinc-selenium nanoparticles on microalgae Scenedesmus quadricauda. In: Cerkal R, Belcredi NB, Prokešová L, Vacek P (eds) MendelNet 2017: proceedings of the 24th international PhD students conference, 8-9 November 2017, Brno. Mendel University, Brno, p 669-674

* Thorisson S, Gunstone F, Hardy R (1992) The antioxidant properties of ethoxyquin and some of its oxidation products in fish oil and fish meals. J Am Oil Chem Soc 69: 806-809

UNECE (United Nations Economic Commission for Europe) (2005) UN Model Regulations, Vol 1, 14th edn (revised): recommendations on the transport of dangerous goods. UNECE, Geneva

US EPA (United States Environmental Protection Agency) (2004) Prevention, pesticides and toxic substances (7508C). RED facts: ethoxyquin. EPA-738-F-04-006, November 2004. US Environmental Protection Agency, Washington DC

*US EPA (United States Environmental Protection Agency) (2012) Quantitative risk assessment calculations. In: Sustainable Futures /P2 Framework Manual, EPA-748-B12001, Chapter 13. Office of Chemical Safety and Pollution Prevention, US EPA, Washington DC

*Wang J, Ai Q, Mai K, Xu W and others (2010) Effects of dietary ethoxyquin on growth performance and body composition of large yellow croaker Pseudosciaena crocea. Aquaculture 306:80-84

*Wang J, Ai Q, Mai K, Xu H and others (2015) Effects of dietary ethoxyquin on growth, feed utilization and residue in the muscle of juvenile Japanese seabass, Lateolabrax japonicus. Aquacult Res 46:2656-2664

WHO (World Health Organisation) (2012) Safety evaluation of certain food additives and contaminants. Seventyfourth meeting of the Joint FAO/WHO Expert Committee on Food Additives (JECFA), WHO food additives series 65. WHO, Geneva

Yamashita Y, Katagiri T, Pirarat N, Futami K, Endo M, Maita M (2009) The synthetic antioxidant, ethoxyquin, adversely affects immunity in tilapia (Oreochromis niloticus). Aquacult Nutr 15:144-151

Submitted: February 20, 2018; Accepted: August 9, 2018 Proofs received from author(s): September 19, 2018 